\title{
Knowledge and practice of emergency contraception among female students of public university of Ouagadougou, Burkina Faso, West Africa
}

\author{
Yobi Alexis Sawadogo ${ }^{1 *}$, Issa Ouedraogo ${ }^{1}$, Sibraogo Kiemtore ${ }^{1}$, Fatou Ouedraogo ${ }^{2}$, Boubakar \\ Toure ${ }^{1}$, Adama Ouattara1, Dantola Paul Kain ${ }^{1}$, Charlemagne R. Marie Ouedraogo ${ }^{1}$
}

\begin{abstract}
${ }^{1}$ Department of Obstetrics and Gynecology, Unity of Training and Research in Health Sciences of University Ouaga I Professor Joseph KI-ZERBO, Ouagadougou, Burkina Faso, West Africa

${ }^{2}$ General practitioner at Medical Center of University Ouaga I Professor Joseph KI-ZERBO, Ouagadougou, Burkina Faso, West Africa
\end{abstract}

Received: 23 October 2018

Accepted: 28 November 2018

\section{*Correspondence:}

Dr. Sawadogo Yobi Alexis,

E-mail: sawalexis@yahoo.fr

Copyright: ( ) the author(s), publisher and licensee Medip Academy. This is an open-access article distributed under the terms of the Creative Commons Attribution Non-Commercial License, which permits unrestricted non-commercial use, distribution, and reproduction in any medium, provided the original work is properly cited.

\section{ABSTRACT}

Background: Female students are exposed to unsafe sex, sources of unwanted pregnancy and abortions. It is recognized that emergency contraception can effectively prevent pregnancy. The purpose of this study was to evaluate the knowledge and practices of Ouagadougou public university students in relation to emergency contraception in order to propose solutions to reduce the proportion of unwanted pregnancies among female students.

Methods: This was a cross-sectional study conducted between May 1st and October 31st, 2016 in the public universities of Ouagadougou. A questionnaire was administered to a sample of 732 students randomly selected.

Results: The average age of female students was 22.7 years old. The age group 19 to 24 was the most represented $(68.03 \%)$. Of the students surveyed, $87 \%$ knew or had heard of emergency contraception. The students only used the emergency contraceptive pill. The emergency contraceptive use rate was $44.42 \%$. Approximately, $83 \%$ of users were aware of the delay in using emergency contraception. The reasons for using emergency contraception were condom breakage $(25.10 \%)$ and unprotected sex $(74.9 \%)$. Female students purchased the contraceptive directly in pharmacies (93.61\%).

Conclusions: Emergency contraception gives women a last chance to avoid an unwanted pregnancy after unprotected sex. Awareness and free availability of emergency contraception (EC) could improve the reproductive health of female students.

Keywords: Emergency, Contraception, Ouagadougou, Students, Universities

\section{INTRODUCTION}

Sexual activity has started increasingly early., ${ }^{1,2}$ A document published by the Ministry of Health in 2008, revealed that in the 15-19 age range between 1996 and 2006, there was a considerable increase in the proportion of sexually active women, exposing, earlier and for a longer period of time, these women to reproductive events (unwanted pregnancy and abortion). ${ }^{1}$ Approximately 42 million abortions take place each year worldwide, of which nearly 20 million are unsafe and responsible for 70,000 maternal deaths. Students are particularly exposed to risky sex; behaviours that result in unwanted pregnancies, abortions and sexually transmitted infections including HIV / AIDS. $^{2}$ Virtually all deaths and cases of disability due to abortion could be prevented 
by sex education, the use of effective contraceptives. ${ }^{3}$ It is estimated that about 214 million women in developing countries want to delay the time to have a child or to have no more children but who do not use contraception. ${ }^{4}$ In Africa, $23.5 \%$ of women of childbearing age have an unmet need for modern contraceptives. ${ }^{4}$ Thus, the need to promote reproductive health of young people, the Ministry of Health of Burkina Faso has intensified its actions through several strategies such as the strategic plan for securing reproductive health products 20062015, and the national plan of Family Planning Revitalization 2013-2015..$^{5}$ Despite these efforts, it is clear that the contraceptive rate remains low. The results of the fourth Demographic and Health Survey reported a contraceptive prevalence of $15 \%$ in 2010 , of which $14 \%$ for modern contraception. ${ }^{6}$ In view of this, the promotion of emergency contraception could contribute to the reduction of unwanted pregnancies. Indeed, emergency contraception (EC) prevents $95 \%$ of pregnancies when it is taken within 5 days of intercourse. ${ }^{7}$ Wanting to contribute to the reduction of unwanted pregnancies in a student environment, we initiated this work, which evaluated the knowledge of female students at public universities in Ouagadougou on emergency contraception and their practices.

\section{METHODS}

This study was carried out in the public universities of Ouagadougou in Burkina Faso (University Ouaga I Professor Joseph KI ZERBO and University Ouaga II) This was a cross-sectional descriptive study that took place from March 1st to October 31st, 2016. The study population was students regularly enrolled in the public universities of Ouagadougou, during the year 2015-2016. Regularly enrolled students who voluntarily accepted and completed the survey cards were included in present study. Female students whose survey cards were incompletely completed (68 cases) were excluded from the study.

Present study was conducted in the health service of the National Center of University Works located in the public universities of the city of Ouagadougou in Burkina Faso. The data were collected using a written and anonymous questionnaire and administered after a pre-test performed on 45 female students.

The questionnaires were completed by the students themselves and then collected on the spot. According to a previous study in 2012, the prevalence of emergency contraception was $35.2 \%$ in the student environment ( $\mathrm{p}=$ $0.352)$.

Using the Schwartz formula $n=z^{2} p(1-p) / e^{2}(z=1.96$, e $=0.05$ accepted margin of error $)$, the minimum sample size to obtain a representative sample of students was 351 individuals. This minimum size was corrected by the $5 \%$ no response rate. The estimated minimum size was 369 students. We included 732 students.
The data were collected using a written and anonymous questionnaire and administered after a pre-test performed on 45 female students. The cards were completed by the students themselves and then retrieved immediately afterwards.

Variables such as sociodemographic characteristics, gynecological history, knowledge on emergency contraception, use of emergency contraception were reported. On the ethical front, the conditions for collecting and keeping the information respected the fundamental principles of human rights. The anonymity of the questionnaire and the confidentiality of the data have been respected. The approval of the ethics committee was obtained before the completion of this work.

\section{RESULTS}

\section{Sociodemographic characteristics}

During this study period, we surveyed 732 students. The age of female students ranged from 19 to 35 with an average age of 22.7 years. Female undergraduates were the most numerous with $82.38 \%$. Table 1 gives the distribution of female students by different characteristics.

Table I: Distribution of female students by sociodemographic characteristics.

\begin{tabular}{|l|l|l|}
\hline Characteristics & Number & Percentage \\
\hline Age & 498 & 68.03 \\
\hline 25-29 years & 197 & 26.91 \\
\hline 30-35 years & 37 & 5.05 \\
\hline Total & 732 & 100 \\
\hline Cycle level & & \\
\hline $1^{\text {st }}$ cycle & 603 & 82.38 \\
\hline $2^{\text {nd }}$ cycle & 129 & 17.62 \\
\hline Marital status & & \\
\hline Single & 659 & 90.03 \\
\hline Marital life & 73 & 9.97 \\
\hline Religion & & \\
\hline Christian & 331 & 45.22 \\
\hline Muslim & 385 & 52.60 \\
\hline Animist & 11 & 1.50 \\
\hline Jehovah's Witness & 5 & 0.68 \\
\hline Residence & & \\
\hline University campus & 135 & 18.44 \\
\hline In family & 237 & 32.38 \\
\hline Rented house & 95 & 12.98 \\
\hline Guardian's court & 191 & 26.10 \\
\hline At a friend's house & 74 & 10.11 \\
\hline
\end{tabular}

\section{Student knowledge of emergency contraception}

Regarding emergency contraception, 637 students representing $87.02 \%$, said they had heard about it. 
Of these, 389 (61.07\%) knew the definition of emergency contraception. Female students who could not correctly define emergency contraception accounted for about $39 \%$. Figure 1 gives the distribution of female students by source of information on emergency contraception (EC). Almost all the students who have ever heard of EC $(98.90 \%)$ knew the utility. Only 7 students (1.1\%) thought that the role of $\mathrm{EC}$ was to regulate the menstrual cycle. Regarding the use of EC, $81.94 \%$ of female students knew the mode of administration, $8.63 \%$ had a false knowledge and $9.42 \%$ of female students had no idea.

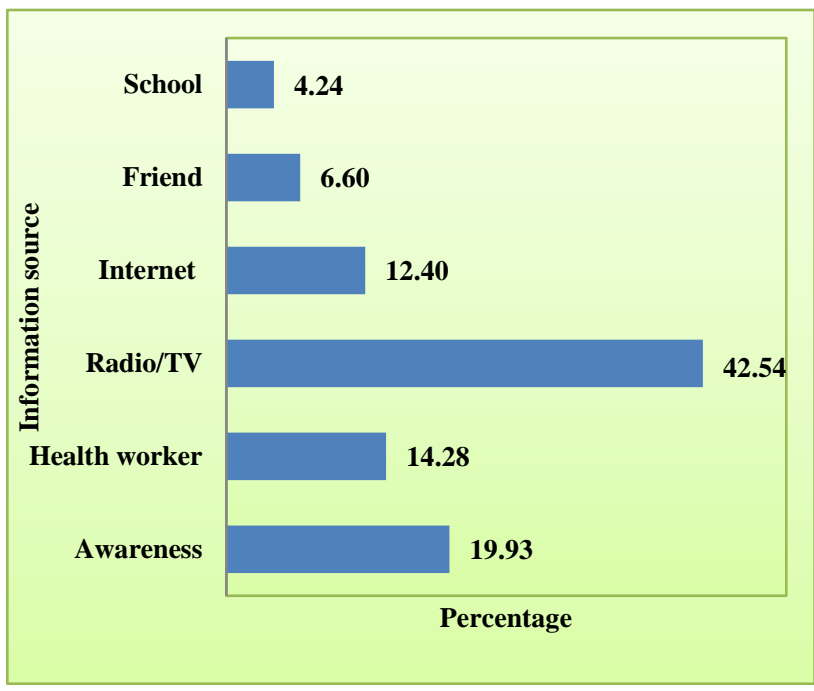

Figure 1: Distribution of female students by source of information on emergency contraception.

Figure 2 presents the assessment of the effectiveness of emergency contraception by female students. The results of assessment of EC use period by students is given in the figure 3.Only 152 students $(23.86 \%)$ said that emergency contraception has adverse effects that would be menstrual disorders, cancer, abortions, infertility. Is information on emergency contraception available?

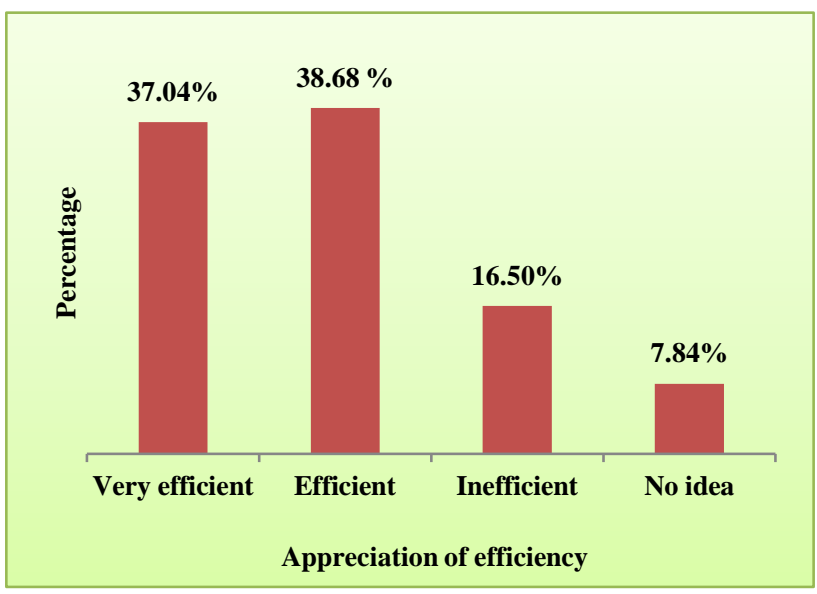

Figure 2: Distribution of female students according to the opinion on the effectiveness of emergency contraception.
In this question, the majority of respondents, $83.47 \%$, said they had not received enough information about emergency contraception.

They proposed the organization of awareness sessions on emergency contraception. Only $16.53 \%$ said that this information was available.

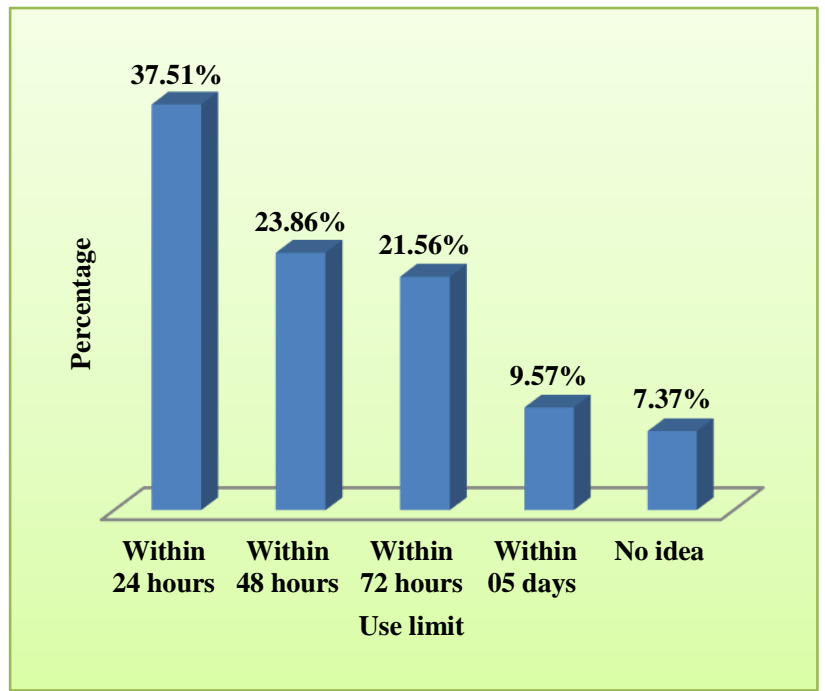

Figure 3: Distribution of female students according to the knowledge of the time of use.

\section{Student practices of emergency contraception}

Of the 732 students, 529 reported being sexually active $(72.27 \%)$. The average age of first intercourse for these students was 17.6 years. About $15 \%$ of these students $(14.93 \%)$ reported having an abortion at least once.

Only 23 students $(4.35 \%)$ said they had consulted in a health center for emergency contraception. These are students who have had sexual intercourse without their consent and those who have been scared after consensual sex.

As for the use of emergency contraception, 235 students (44.42\%) reported having already used the EC against 55.58 who never used it. Reasons for using contraception included condom breakage $(25.10 \%)$ and unprotected sex $(74.9 \%)$.

For EC users, the number of uses is listed in Table 2. The students (220) obtained their emergency contraceptive pills in pharmacies without prescription representing $93.61 \%$. Other sources accounted for $6.38 \%$.

After taking emergency contraception, 181 or $77.02 \%$ reported that they had seen their periods in advance, $20 \%$ had them at the correct date, and only $2.98 \%$ of women had a menstrual period delay. Of 235 emergency contraceptive users, 103 students $(43.90 \%)$ had sought the opinion of the sexual partner before taking the contraceptive. 
The opinion of the partner was not collected before the use of emergency contraception, in $56,10 \%$ of female students.

Table 2: Distribution of female students by number of EC uses.

\begin{tabular}{|l|l|l|}
\hline Number of uses & Number & Percentage \\
\hline Once & 154 & 65.53 \\
\hline 2 times & 49 & 20.85 \\
\hline 3 times & 24 & 10.21 \\
\hline Over 3 times & 8 & 3.40 \\
\hline Total & 235 & 100 \\
\hline
\end{tabular}

Among UC users, $21.70 \%$ of female students do not believe in the reliability of the emergency contraceptive pill and $50.06 \%$ said that taking EC is not a good practice.

Figure 4 shows the distribution of users by time of use after sexual intercourse.

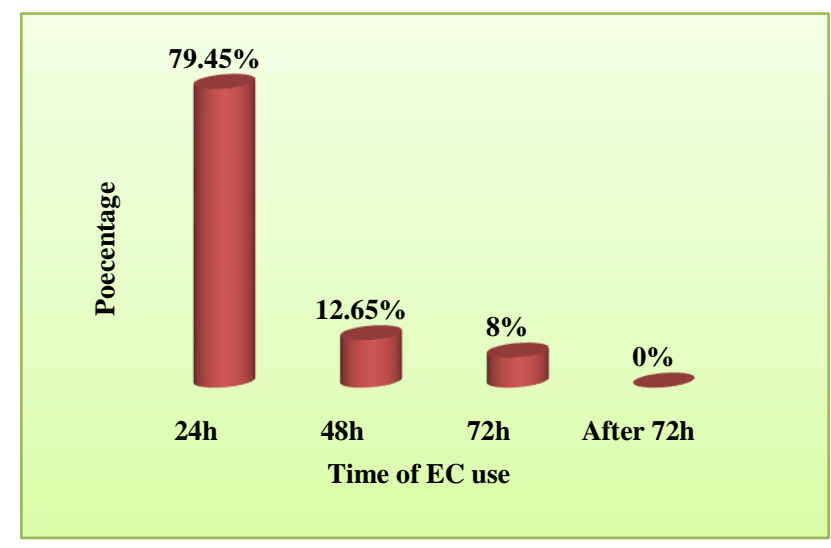

Figure 4: Distribution of students according to the Time of emergency contraception use after intercourse.

\section{DISCUSSION}

Nearly 9 out of 10 students $(87.02 \%)$ had heard of emergency contraception. This rate is higher than those of Ekok et al, Ezebialu and Eke in Nigeria, Addo et al in Ghana who found respectively $71.2 \%, 51.6 \%$ and $51.4 \% .^{2,9,10}$ It is lower than that of Veloso et al in Brazil [1] which was $96 \%$. The sources of information for students varied by series. In our series, the media is the main source of information $(42.54 \%)$ while in Nigeria it is the peers and friends with $51 \% .^{9}$

Sexually active female students accounted for $72.27 \%$. This rate is comparable to that of Ekok et al in Nigeria which is $69.2 \%$. It is higher than those of Veloso et al in Brazil, Ezebialu and Eke in Southeast Nigeria and Gupta et al in India which are respectively $60 \%, 21.8 \%$ and $1 \% .^{1,2,8,9}$ This high rate is explained by the Westernization of African society. Indeed, African culture and different religions do not tolerate sex outside marriage.

Female students who consulted in health center for emergency contraception accounted for only $4.35 \%$, yet $44.42 \%$ of female students reported having used emergency contraception. Procurement of emergency contraception was directly in pharmacy without prescription in $93,68 \%$. This could be explained by the fact that the emergency contraceptive pill is sold over the counter in pharmacies on the one hand, and on the other hand by the persistence of sociocultural restraints that are unfavorable to sex outside marriage. Indeed, some students, for reasons of modesty, and unwilling to expose themselves to the accusing eyes of other people do not go to health centers to obtain emergency contraception.

The reasons for using contraception are condom breakage (25.10\%) and unprotected sex (74.9\%). According to Moreau $\mathrm{C}$, in France, the main reasons are slippage or condom breakage $(30.7 \%)$ and forgetfulness of taking a pill $(30.1 \%){ }^{11}$ Unprotected sex, as a reason for taking EC, was between $18 \%$ and $23.5 \%$ depending on the age of the woman. ${ }^{11}$ As a result, students take considerable risks, exposing themselves to sexually transmitted infections, including HIV.

The use of emergency contraception remains most often unique. The majority of users use it only once. In our series $65.53 \%$ took emergency contraception once, Onefifth of users $(20.85 \%)$ took it twice and $13.61 \%$ reported using it three or more times. Our results corroborate with those of Caroline Moreau in France who found in her study that the rates of users who had taken emergency contraception one, two, three times and more, are respectively $67.3 \% ; 21.7 \%$ and $11 \% .^{11}$

The multiple use of emergency contraception is explained by the fact that the majority of female students being single, their sexual relations with men are usually casual and unprotected.

Only $21.66 \%$ of female students who had heard about EC knew about EC if it was effective within 72 hours of having sex. Fortunately, all EC users knew the time to use. This rate is lower than those of Ekok et al in Nigeria and Veloso et al in Brazil which were respectively $51.7 \%$ and $88.76 \%$; but it is higher than that of Ezebialu and Eke in South-East Nigeria which is $9.5 \% .^{1,2,9}$

Before the use of UC, sexual partner's opinion was collected by $45.90 \%$ of female students. This result indicates that most students have occasional sex and do not involve their partners sufficiently in decision making for emergency contraception.

Only $78.3 \%$ of student users reported that emergency contraception is effective. Indeed, emergency contraception is not $100 \%$ effective. Its effectiveness is greater if it is taken early after unprotected sex. ${ }^{7}$ The 
effectiveness of emergency contraception is usually calculated by comparing the number of pregnancies observed after the use of emergency contraception $(\mathrm{O})$ to the number of pregnancies expected in its absence (A), using the following formula: $1-\mathrm{O} / \mathrm{A} .^{12}$

In our series, about $20 \%$ of female students reported that emergency contraception is not a good practice. This is related to the socio-cultural context in which the students live. The most common opinion equates emergency contraception with an abortive method. The same view was put forward by the US Food and Drug Administration at the time of George Bush. ${ }^{13}$

\section{CONCLUSION}

Emergency contraception gives women a last chance to avoid an unwanted pregnancy after unprotected sex. This is a method that is not very well known by students limiting its use. The main reason for users is unprotected sex. Because of the early onset of sexual intercourse and low contraceptive prevalence among female students, actions should be considered to increase awareness and promote this ultimate contraception.

Funding: No funding sources

Conflict of interest: None declared

Ethical approval: The study was approved by the Institutional Ethics Committee

\section{REFERENCES}

1. Veloso DL, Peres VC, de Camargo JD, Guimarães JV, Salge AK. Emergency contraception: knowledge and attitudes of nursing students. Rev. Gaúcha Enferm. 2014;35(2):33-9.

2. Ekok F.A, Ndep A. O, Adindu A. Emergency Contraceptive Use among Female Undergraduate Students at the University of Calabar, Calabar, Nigeria. J Health Med Nursing. 2016;31:19-24

3. WHO Prevention of Unsafe Abortion, February 2018 Available on http://www.who.int/fr/news-room/factsheets/detail/preventing-unsafe-abortion

4. WHO Family Planning / Contraception; February 2018 Available on http://www.who.int/fr/news- room/fact-sheets/detail/family-planningcontraception

5. Ministry of Health Burkina Faso. Mother and Child Health Branch. Strategic plan for securing reproductive health products 2009- 2015; $2010: 92$.

6. National Institute of Statistics and Demography (INSD), Ministry of Economy and Finance: Demographic and Health Survey and Multiple Indicators.Ouagadougou, ICF International. Calverton, Maryland, USA, 2012:379

7. WHO. Emergency Contraception, February 2018, Available on http://www.who.int/fr/news-room/factsheets/detail/emergency-contraception

8. Gupta RK, Raina SK, Verma AK, Shora T. Emergency contraception: Knowledge and attitude toward its use among medical students of a medical college in North-West India. J Pharm Bioall Sci 2016;8(3):235-9.

9. Ezebialu IU, Eke AC. Knowledge and practice of emergency contraception among female undergraduates in south eastern Nigeria. Annals of medical and health sciences research. 2013;3(4):5415 .

10. Addo VN, Tagoe-Darko ED. Knowledge, practices, and attitudes regarding emergency contraception among students at a university in Ghana. Int $\mathbf{J}$ Gynecol Obstet. 2009;105(3):206-9.

11. Moreau C, Lydié N, Warszawski J, Bajos N. Sexual Activity, STIs, Contraception: A Stabilized Situation, Health Barometer 2005;329-53

12. Trussell J, Raymond EG, Cleland K. Emergency contraception: a last chance to prevent unintended pregnancy. Contemporary Readings Law Social Justice. 2014;6(2).

13. Ackerman T, Emergency contraception: Science and religion collide. Ann Emerg Med.2006;47(2):154-6.

Cite this article as: Sawadogo YA, Ouedraogo I,

Kiemtore S, Ouedraogo F, Toure B, Ouattara A, et al.

Knowledge and practice of emergency contraception among female students of public university of

Ouagadougou, Burkina Faso, West Africa. Int J Reprod Contracept Obstet Gynecol 2019;8:135-9. 